OPEN ACCESS

Edited by:

Sabine Fillinger,

National Institute of Agricultural

Research, France

Reviewed by:

Mario A. Pagnotta,

Tuscia University, Italy

Julien Carpezat

Terres Inovia, France

${ }^{*}$ Correspondence:

George S. Karaoglanidis gkarao@agro.auth.gr

Specialty section:

This article was submitted to Antimicrobials, Resistance

and Chemotherapy,

a section of the journal

Frontiers in Microbiology

Received: ОЗ September 2016

Accepted: 28 October 2016

Published: 15 November 2016

Citation:

Samaras A, Madesis P and Karaoglanidis GS (2016) Detection

of sdhB Gene Mutations in SDHI-Resistant Isolates of Botrytis cinerea Using High Resolution Melting

(HRM) Analysis.

Front. Microbiol. 7:1815.

doi: 10.3389/fmicb.2016.01815

\section{Detection of sdhB Gene Mutations in SDHI-Resistant Isolates of Botrytis cinerea Using High Resolution Melting (HRM) Analysis}

\author{
Anastasios Samaras ${ }^{1}$, Panagiotis Madesis ${ }^{2}$ and George S. Karaoglanidis ${ }^{1 *}$ \\ ${ }^{1}$ Faculty of Agriculture, Forestry and Natural Environment, Laboratory of Plant Pathology, Aristotelian University of \\ Thessaloniki, Thessaloniki, Greece, ${ }^{2}$ Institute of Applied Biosciences, Centre for Research and Technology Hellas, \\ Thessaloniki, Greece
}

Botrytis cinerea, is a high risk pathogen for fungicide resistance development. Pathogen' resistance to SDHIs is associated with several mutations in sdh gene. The diversity of mutations and their differential effect on cross-resistance patterns among SDHIs and the fitness of resistant strains necessitate the availability of a tool for their rapid identification. This study was initiated to develop and validate a high-resolution melting (HRM) analysis for the identification of $\mathrm{P} 225 \mathrm{H} / \mathrm{F} / \mathrm{L} / \mathrm{T}$, N230l, and $\mathrm{H} 272 \mathrm{~L} / \mathrm{R} / \mathrm{Y}$ mutations. Based on the sequence of $s d h \mathrm{~B}$ subunit of resistant and sensitive isolates, a universal primer pair was designed. The specificity of the HRM analysis primers was verified to ensure against the cross-reaction with other fungal species and its sensitivity was evaluated using concentrations of known amounts of mutant's DNA. The melting curve analysis generated nine distinct curve profiles, enabling the discrimination of all the four mutations located at codon 225, the N230l mutation, the three mutations located in codon 272, and the non-mutated isolates (isolates of wild-type sensitivity). Similar results were obtained when DNA was extracted directly from artificially inoculated strawberry fruit. The method was validated by monitoring the presence of sdhB mutations in samples of naturally infected strawberry fruits and stone fruit rootstock seedling plants showing damping-off symptoms. HRM analysis data were compared with a standard PIRA-PCR technique and an absolute agreement was observed suggesting that in both populations the $\mathrm{H} 272 \mathrm{R}$ mutation was the predominant one, while $\mathrm{H} 272 \mathrm{Y}$, N23OI, and $\mathrm{P} 225 \mathrm{H}$ were detected in lower frequencies. The results of the study suggest that HRM analysis can be a useful tool for sensate, accurate, and rapid identification of several sdhB mutations in $B$. cinerea and it is expected to contribute in routine fungicide resistance monitoring or assessments of the effectiveness of anti-resistance strategies implemented in crops heavily treated with botryticides.

Keywords: boscalid, fungicide resistance, gray mold, strawberry, succinate dehydrogenase gene

\section{INTRODUCTION}

Botrytis cinerea Pers. ex Fr (teleomorph Botryotinia fuckeliana de BaryWhetz) the causal agent of gray mold disease, is an ubiquitous pathogen attacking more than 200 host plants. Within its host range are included some of the economically most important crops grown in field or in greenhouse, such as grapes, tomatoes, lettuce, strawberries, apples, pears, as well as several ornamental plants 
etc. Under favorable climatic conditions the fungus expands rapidly and may lead to devastating yield losses (Dean et al., 2012). An integration of cultural control methods may be used to combat the disease, such as environmental manipulation and sanitation, however, besides these preventive measures, chemical control remains the main tool for the successful disease management under conditions favorable for the development of the pathogen.

Fungicides belonging in several chemical groups are registered for use against the pathogen in most places of the world (Hahn, 2014). Among them, SDHIs represent the latest addition in the growers' quiver against the pathogen. They are currently the fastest growing fungicide group, including, in total 18 compounds (FRAC, 2016). Boscalid was the first SDHI molecule used against the pathogen in 2007, while later on fluopyram, isopyrazam, and penthiopyrad were also introduced as botryticides (Stammler et al., 2008; Veloukas and Karaoglanidis, 2012; Fillinger and Walker, 2016). Molecules belonging in the SDHI group share a common mode of action, consisting in the inhibition of respiration by inhibiting complex II, also known as succinate dehydrogenase, in the respiratory chain that leads to the block of the cell energy production (Cecchini, 2003).

However, the polycyclic nature of the disease, the high genetic variability, the abundant sporulation, the short generation time of the pathogen and the necessity for repetitive spray applications under favorable environmental conditions for disease development are factors contributing to a high risk for resistance development to site-specific fungicides used for its control. Indeed, in the past $B$. cinerea populations originating from several hosts such as grapes, strawberries, or tomatoes, throughout the world, have developed resistance to all the groups of site-specific fungicides used as botryticides that was associated with either target site modifications or overexpression of drugefflux transporters (Leroux, 2007; Hahn, 2014; Fillinger and Walker, 2016).

SDHIs are considered to be of medium to high risk for resistance development. Resistance to boscalid, the first SDHI molecule introduced as a botryticide, emerged soon after the onset of its use. Currently, resistance to SDHIs has been reported in $B$. cinerea populations originating from table grapes, strawberry, tomato, lettuce, kiwi fruit, and apple fruit in several European and North or South America countries (Bardas et al., 2010; Kim and Xiao, 2010; Leroux et al., 2010; Leroch et al., 2011; Veloukas et al., 2011; Fernandez-Ortuno et al., 2012; Chatzidimopoulos et al., 2013; Amiri et al., 2014; De Miccolis Angelini et al., 2014b; Hahn, 2014; Konstantinou et al., 2015). Sequence analysis of the four $s d h$ subunits in SDHI-resistant strains revealed that resistance was associated with nine target site mutations located in the $s d h \mathrm{~B}$ subunit and one mutation in the $s d h \mathrm{D}$ subunit. In the $s d h \mathrm{~B}$ subunit mutations associated with resistance to SDHIs have been detected at codons 225, 230, and 272 (Leroux et al., 2010; Veloukas et al., 2011; De Miccolis Angelini et al., 2014a; Esterio et al., 2015). At codon 225 the proline can be substituted by phenylalanine (P225F), leucine (P225L), threonine (P225T), or histidine (P225H). At codon 230 a single mutation has so far been detected, the substitution of asparagine by isoleucine (N230I), while at codon 272 the histidine may be replaced by arginine (H272R), tyrosine (H272Y), leucine $(\mathrm{H} 272 \mathrm{~L})$, or valine $(\mathrm{H} 272 \mathrm{~V})$. In the $s d h \mathrm{D}$ subunit the replacement of histidine by arginine at codon 132 (H132R) has been found to be associated with resistance to SDHIs in B. cinerea (Leroux et al., 2010).

For the detection of these mutations several techniques have so far, been developed. These techniques include direct sequencing of the four $s d h$ subunits of $B$. cinerea (Leroux et al., 2010), allele-specific PCR enabling specific detection of two of the most common mutations associated with resistance to SDHIs in B. cinerea, $\mathrm{H} 272 \mathrm{R} / \mathrm{Y}$ (Yin et al., 2011), and a PIRA-PCR technique developed for the detection of H272L/R/Y, N230I, and P225F mutations (Veloukas et al., 2011). The above mentioned techniques require the fungal isolation, while multiple reactions are necessary to identify the mutations associated with the resistance. In addition to the above mentioned techniques, a newer method, that of pyrosequencing, was developed offering the advantage of quantification of several $s d h \mathrm{~B}$ mutations in B. cinerea populations (Gobeil-Richard et al., 2015)

High Resolution Melting Analysis (HRM) is a novel and powerful molecular technique that has been introduced in 2002 and currently represents one of the simplest methods for genotyping, mutation scanning, and sequence matching (Reed et al., 2007; Taylor, 2009; Mondini et al., 2011). It is a PCR-based closed tube method that identifies variations in DNA sequence by measuring changes in fluorescence level of the melting DNA amplicon (Mondini et al., 2012; Sakaridis et al., 2014). Prior to HRM analysis, the region of interest is amplified using PCR in the presence of a dsDNA binding dye, while after PCR, melting curves are generated by monitoring the fluorescence of the binding dye in the presence of dsDNA. The whole process is monitored by a specific HRM instrument's software resulting in a characteristic melting profile of the amplicon (Reed et al., 2007; Ganopoulos et al., 2012). Changes in the shape of the melting curves are due to differences in the sequence of the PCR amplicon (length, GC content, and actual sequence), (Mondini et al., 2015). HRM analysis has several advantages over other genotyping and scanning methods and due to these advantages has already started to be applied in several research aspects of plant pathology that include pathogen diagnosis and identification (Bester et al., 2012; Gori et al., 2012; Wong et al., 2013; Papavasileiou et al., 2016) or detection of mutations associated with resistance of plant pathogens to fungicides (Curvers et al., 2015).

Recently, an HRM assay has been developed and used for the detection of resistance to SDHIs in $B$. cinerea (Chatzidimopoulos et al., 2014). However, the developed assay was restricted only, in the detection of $\mathrm{H} 272 \mathrm{R} / \mathrm{Y}$ mutations. Therefore, a study was initiated aiming to investigate whether an expansion of the detection spectrum is possible, by developing a single HRM assay for the simultaneous detection and identification of eight mutations located in the $s d h \mathrm{~B}$ subunit of $B$. cinerea that are associated with resistance to SDHIs. The accuracy of the developed assay was evaluated by identifying the $s d h \mathrm{~B}$ mutations in $B$. cinerea samples obtained from strawberry fruit and stone fruit rootstock seedlings attacked by the pathogen. 


\section{MATERIALS AND METHODS}

\section{Fungal Isolates}

For the development of the method,14 B. cinerea isolates that were resistant to SDHIs and possessed eight distinct $s d h \mathrm{~B}$ mutations (P225H/F/L/T, N230I, and $\mathrm{H} 272 \mathrm{~L} / \mathrm{R} / \mathrm{Y}$ ) and two isolates that were sensitive to SDHIs (isolates of wild-type sensitivity) were included in the study. Most of the isolates had been collected from Greek strawberry fields or stone fruit rootstocks cultivated in the greenhouse, for the requirements of monitoring studies aiming to identify $s d h \mathrm{~B}$ mutations associated with resistance to SDHIs (Veloukas et al., 2011; Konstantinou et al., 2014, 2015). The $s d h \mathrm{~B}$ mutations had been identified using a PIRA-PCR technique described previously (Veloukas et al., 2011) or direct sequencing of the $s d h \mathrm{~B}$ gene (Leroux et al., 2010). The isolates possessing the P225L and P225T mutations were originating from Germany. All the isolates were identified as B. cinerea using a duplex PCR assay developed by Plesken et al. (2015). A complete list of the isolates used in the study and their origin is provided in Table 1.

\section{Sequencing of the Isolates}

To confirm the identification obtained using the PIRAPCR technique and to determine the specific nucleotide polymorphisms associated with each amino acid change the entire $s d h B$ sequence was amplified using the primer pair IpBcBeg (5'-CCACTCCTCCATAATGGCTGCTCTCCGC$\left.3^{\prime}\right)$ and IpBcEnd 2 (5'-CTCATCAAGCCCCCTCATTGATATC$3^{\prime}$ ) designed by Leroux et al. (2010). Amplification conditions

TABLE 1 | List of Botrytis cinerea isolates used for the development of the assay.

\begin{tabular}{|c|c|c|c|}
\hline Isolate code & sdhB mutation ${ }^{a}$ & Year of isolation & Origin \\
\hline BcSV10 & Wild-type & 2014 & strawberry \\
\hline Вс33 & Wild-type & 2010 & strawberry \\
\hline BcSv14 & $\mathrm{H} 272 \mathrm{R}$ & 2014 & strawberry \\
\hline BcTPR48 & $\mathrm{H} 272 \mathrm{R}$ & 2012 & tomato \\
\hline BcSv44 & $\mathrm{H} 272 \mathrm{Y}$ & 2014 & strawberry \\
\hline Bc30 & $\mathrm{H} 272 \mathrm{Y}$ & 2011 & strawberry \\
\hline BcE114 & $\mathrm{H} 272 \mathrm{~L}$ & 2011 & strawberry \\
\hline Bc278 & $\mathrm{H} 272 \mathrm{~L}$ & 2009 & strawberry \\
\hline BcE98 & N230I & 2011 & strawberry \\
\hline BcTKp12 & N230I & 2011 & tomato \\
\hline BcS22 & P225F & 2010 & strawberry \\
\hline $\mathrm{BcS} 24$ & P225F & 2010 & strawberry \\
\hline BcM100 & P225H & 2013 & Cherry rootstock \\
\hline BcM182 & P225H & 2013 & Cherry rootstock \\
\hline $\mathrm{BcB} 1$ & $\mathrm{P} 225 \mathrm{~L}^{\mathrm{b}}$ & - & grape \\
\hline BcB2 & $\mathrm{P} 225 \mathrm{~T}^{\mathrm{b}}$ & - & $\begin{array}{l}\text { Laboratory } \\
\text { induced mutation }\end{array}$ \\
\hline
\end{tabular}

${ }^{a_{s}}$ dhB mutations were identified using a PIRA-PCR technique Neloukas et al., 2011) and confirmed by direct sequencing of sdhB using the primer pair IpBcBegIpBcend (Leroux et al., 2010). b/solates possessing the P225L and P225T mutations were kindly offered to us by Dr. Gerd Stammler (BASF, Limburgerhof, Germany). were performed as those described by Leroux et al. (2010). PCR products were separated by electrophoresis in $1 \%$ agarose gel in $1 \mathrm{x}$ TAE buffer and visualized after ethidium bromide staining under UV light. PCR products were purified using the Qiaquick PCR Purification Kit (Qiagen GmbH, Hilden, Germany). The purified products were subjected to sequencing and sequences were aligned using the computer software package Mega 5.05. The nucleotide polymorphisms associated with each mutation are shown in Figure 1.

\section{Primer Design and HRM Conditions}

Based on the sequence of the $s d h \mathrm{~B}$ subunit of a reference strain (B05.10) a primer set was designed (sdhB-Fw: GAGGATCGTAAGAAGCTTGATGG and sdhB-Rev: TGTCTT AGTCTCCGCAATTGCC), expected to amplify a 249 bp product. The primer pair was designed using the software program Vector NTI (ThermoFisher Scientific).

PCR amplification, DNA melting and end point fluorescence level acquiring PCR amplifications were performed in a $20 \mathrm{ml}$ volume containing $20 \mathrm{ng}$ of genomic DNA, $4 \mu \mathrm{M}$ of SdhBFw and SdhB-Rev primers, $0.2 \mathrm{mM}$ of each dNTP, $2.5 \mathrm{mM}$ $\mathrm{MgCl}_{2}, 1.5 \mathrm{mM}$ SYTO 9 Green fluorescent nucleic acid stain (Life Technologies Corp.), and 1 U Kapa Taq DNA polymerase (Kapa Biosystems). The PCR amplifications were performed in a Rotor-Gene 6000 real-time 5P HRM PCR thermocycler (Corbett Research) using the following thermal parameters: an initial preheat for $10 \mathrm{~min}$ at $95^{\circ} \mathrm{C}$, followed by 35 cycles at $95^{\circ} \mathrm{C}$ for $20 \mathrm{~s}$, $55^{\circ} \mathrm{C}$ for $20 \mathrm{~s}, 72^{\circ} \mathrm{C}$ for $15 \mathrm{~s}$, and terminated with a final extension at $72^{\circ} \mathrm{C}$ for $10 \mathrm{~min}$. After the PCR amplification, HRM was performed from 80 to $88^{\circ} \mathrm{C}$ rising by $0.1^{\circ} \mathrm{C}$ in each step with a $2 \mathrm{~s}$ hold time for each step with $90 \mathrm{~s}$ of pre-melt conditioning on first step. The HRM data were analyzed with the Rotor-Gene Q series software version 2.3.1 (Qiagen, Milan, Italy). The melting curves were normalized in order to limit the temperature range between the pre- and post-melt regions and eliminate the fluorescence variance. All the reactions were repeated in triplicate.

\section{Assay Specificity}

The specificity of the designed primers was evaluated against several fungal species that can be found on strawberry fruit either as pathogens or contaminants on rotten fruit tissues, such as Alternaria alternata, Rhizopus stolonifer, and Aspergillus niger. The pathogens used were belonging in the fungal culture collection of the Laboratory of Plant Pathology. One isolate of each pathogen was used in the assays. PCR amplifications and the HRM assay were performed using in the same reaction DNA of the above mentioned pathogens along with DNA of $B$. cinerea isolate BcSV10. Amplification and HRM assay conditions were as described previously. Comparison of melting peaks and similarity tests were conducted using Rotor-Gene Q series software version 2.3.1.

\section{Assay Sensitivity}

To determine the detection limits of the developed HRM assay, an analysis was performed using known DNA concentrations of the $\mathrm{H} 272 \mathrm{R}$ mutant BcTPR48 and the isolate of wild-type sensitivityBcSV10. Concentrations of $0.001,0.01,0.1,1,10 \mathrm{ng}$ 


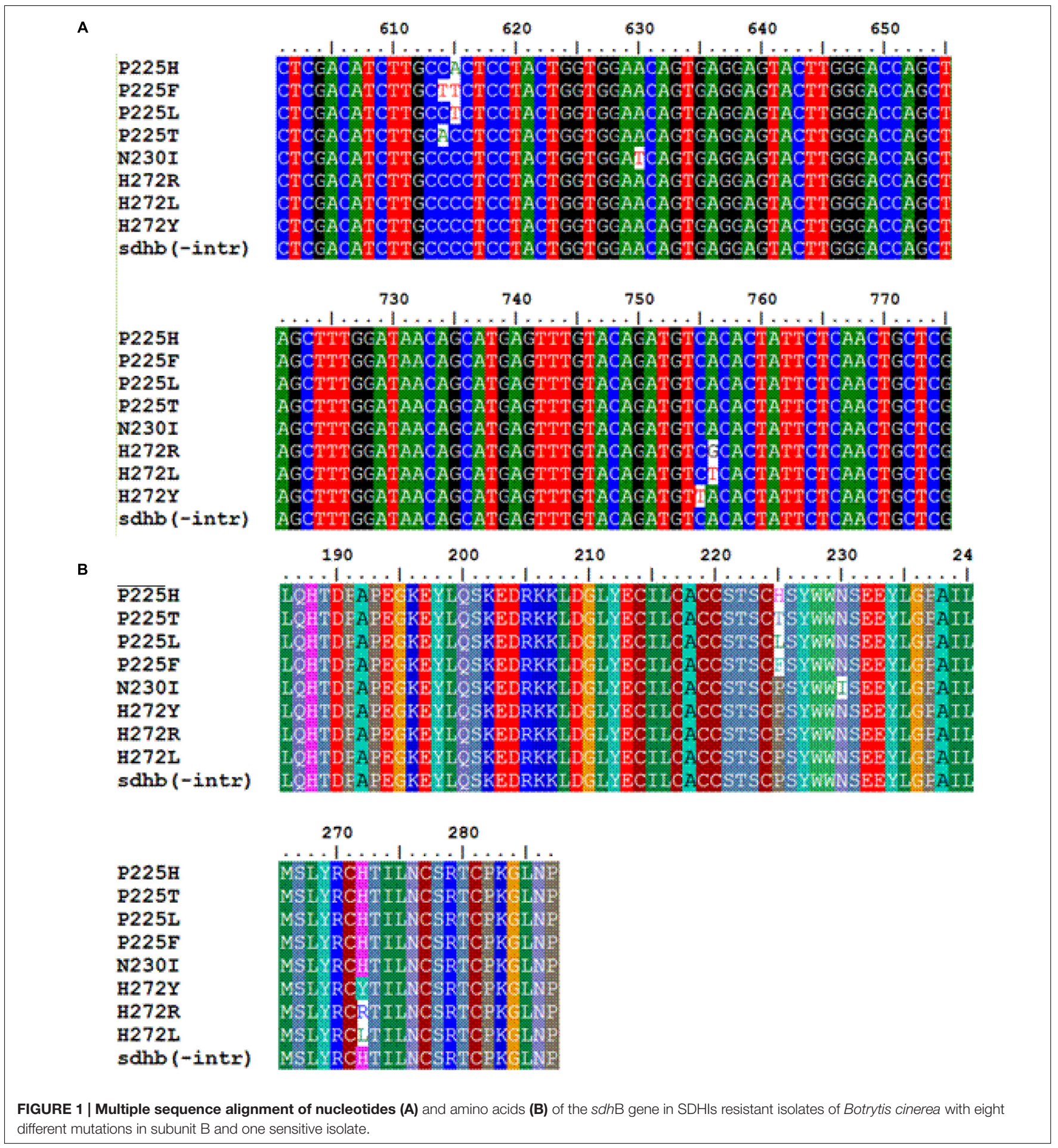

per reaction tube were used. The PCR amplification and HRM analysis conditions were the same as described above.

\section{Application of HRM on DNA Samples Extracted from Fruit Tissues}

The 16 isolates listed in Table 1 that had been used to develop the HRM method using DNA samples from pure fungal cultures were also used to artificially inoculate strawberry fruit (cv. Camarosa). Artificial inoculations and incubation conditions were as described by Veloukas and Karaoglanidis (2012). After the end of the incubation period $100 \mathrm{mg}$ of rotten fruit tissue were removed and used for DNA extraction. The extraction was conducted using Nucleospin Plant II kit (Marchery-Nagel GmbH \& Co.), following the manufacturer's protocol. 
The PCR amplification and HRM analysis conditions were as described previously. To compare melting curves, DNA samples of the $s d h \mathrm{~B}$ mutants that had been extracted from rotten tissue were used in the same reactions along with DNA samples extracted from pure cultures of the mutants. Comparisons of the melting curves were conducted using the Rotor-Gene Q series software version 2.3.1. All the reactions were repeated in triplicate.

\section{Validation of Assay Accuracy in Naturally Infected Strawberry Fruit and Stone Fruit Seedling Samples}

To test the reliability of the developed assay in identifying $s d h \mathrm{~B}$ mutations in field samples, an extensive sampling was conducted during the spring of 2015 in strawberry fields located in the region of Pieria, northern Greece and in greenhouses located in the region of Arta, western Greece, where seedlings of stone fruit rootstocks were growing. Strawberry fruit showing gray mold symptoms were collected, at harvest period, from three different strawberry fields. Similarly, from the greenhouses seedlings showing symptoms of damping - off disease due to $B$. cinerea infection were collected. The strawberry fruit or the stone fruit rootstock seedling plants were transferred to the laboratory in individual polyethylene bags to prevent cross contamination. From each sample a $B$. cinerea single-spore isolate was obtained using a procedure described previously (Myresiotis et al., 2007). In total, 50 and 134 single-spore isolates were collected from strawberry fruit and the rootstock seedlings, respectively. The isolates were characterized as boscalid-resistant or -sensitive using the discriminatory concentration of $2 \mu \mathrm{g} \mathrm{ml}^{-1}$ boscalid, using a procedure previously described (Konstantinou et al., 2015).

From the same fruit or seedling plants used for pathogen isolation, DNA was directly extracted from the rotten tissues as described previously and $s d h \mathrm{~B}$ mutations in the samples were identified following the HRM assay protocol described above. The results of identification using the HRM assay were compared with identification of $s d h \mathrm{~B}$ mutations in the respective samples using a standard PIRA-PCR technique developed by Veloukas et al. (2011). For those samples that identification of $s d h \mathrm{~B}$ mutations was not possible with the PIRA-PCR, direct sequencing of the entire $s d h \mathrm{~B}$ gene was conducted.

\section{RESULTS}

\section{HRM Analysis for the Identification of Mutations in sdhB Gene}

The primer pair SDHB-Fw and SDHB-Rev amplified a 249 bp fragment of the $s d h \mathrm{~B}$ gene in all the nine $B$. cinerea genotypes included in the study. The nine different genotypes were distinguished by a shift in melting temperature axis providing a different melting profile (Figure 2). The HRM analysis generated nine distinct curves, one for each genotype. The shape and profile of normalized curves of each isolate were unique, allowing the discrimination of the $s d h \mathrm{~B}$ mutations (Figure 2A). In addition, the difference graph generated using the wild-type genotype' curve as the baseline, revealed part of the curve sitting outside the $80 \%$ confidence interval (CI) curve, indicating that the several mutants included in the study were, indeed, different (Figure 2B).

\section{Assay Specificity and Sensitivity}

The primer pair SDHB-Fw and SDHB-Rev was designed based on the sequence of the $s d h \mathrm{~B}$ gene of $B$. cinerea. The specificity assay was conducted against pathogens or contaminants that may grow on strawberry fruit such as A. niger, A. alternata, and $R$. stolonifer. The results showed that the designed primer pair was not able to amplify the 249 bp product in any of these fungal organisms but B. cinerea (Figure 3).

The assay was highly sensitive since the $S D H B-F w$ and $S D H B$ Rev specific primers successfully detected down to $0.01 \mathrm{ng}$ of genomic DNA, as shown in the difference graph generated using $0.001 \mathrm{ng}$ of BcTPR48 H272R mutant (Figure 4A) or of the wild-type isolate BcSV10 (Figure 4B), as the reference baseline curve.

\section{HRM Analysis for the Detection of Mutations in sdh Gene of B. cinerea, In planta}

When the developed protocol of HRM analysis was applied using DNA extracted directly from artificially inoculated strawberry fruits as a template, it was also shown to be efficient in discriminating the nine $B$. cinerea genotypes tested. As in the case of DNA extracted from pure cultures, nine distinct curves were generated corresponding to each of the nine genotypes tested. HRM analysis curves which were generated using DNA extracted from the strawberry tissues exhibited high similarity (>90\% CI) to the HRM analysis curves generated using DNA from the pure fungal cultures. Representative HRM analysis curves of DNA originating from pure fungal culture and infected strawberry tissue are provided, as an example, for two out of nine genotypes tested (P225F and H272R) in Figure 5.

\section{Validation of Assay Accuracy in Naturally Infected Strawberry Fruit and Stone Fruit Seedling Samples}

Identification of $s d h \mathrm{~B}$ mutations in $B$. cinerea samples from decayed strawberry fruit or stone fruit rootstock seedling plants showing damping-off symptoms showed that there was a perfect agreement among the novel HRM method and the standard PIRA-PCR method. Resistance detection using a standard bioassay in the 50 isolates obtained from strawberry fruit showed that 20 of them were sensitive to boscalid and the remaining 30 were resistant (Table 2). Similarly, in the 134 isolates obtained from the stone fruit rootstock seedlings, was found that 34 of them were sensitive and the remaining 100 resistant to boscalid (Table 2). The HRM analysis confirmed the presence of 20 and 34 samples without any mutation in $s d h \mathrm{~B}$ subunit, in the $B$. cinerea DNA samples extracted from strawberry fruit and stone fruit rootstock plants, respectively (Table 2). Furthermore, HRM analysis showed that within the DNA samples from strawberry fruit tested there were 18, 11, 

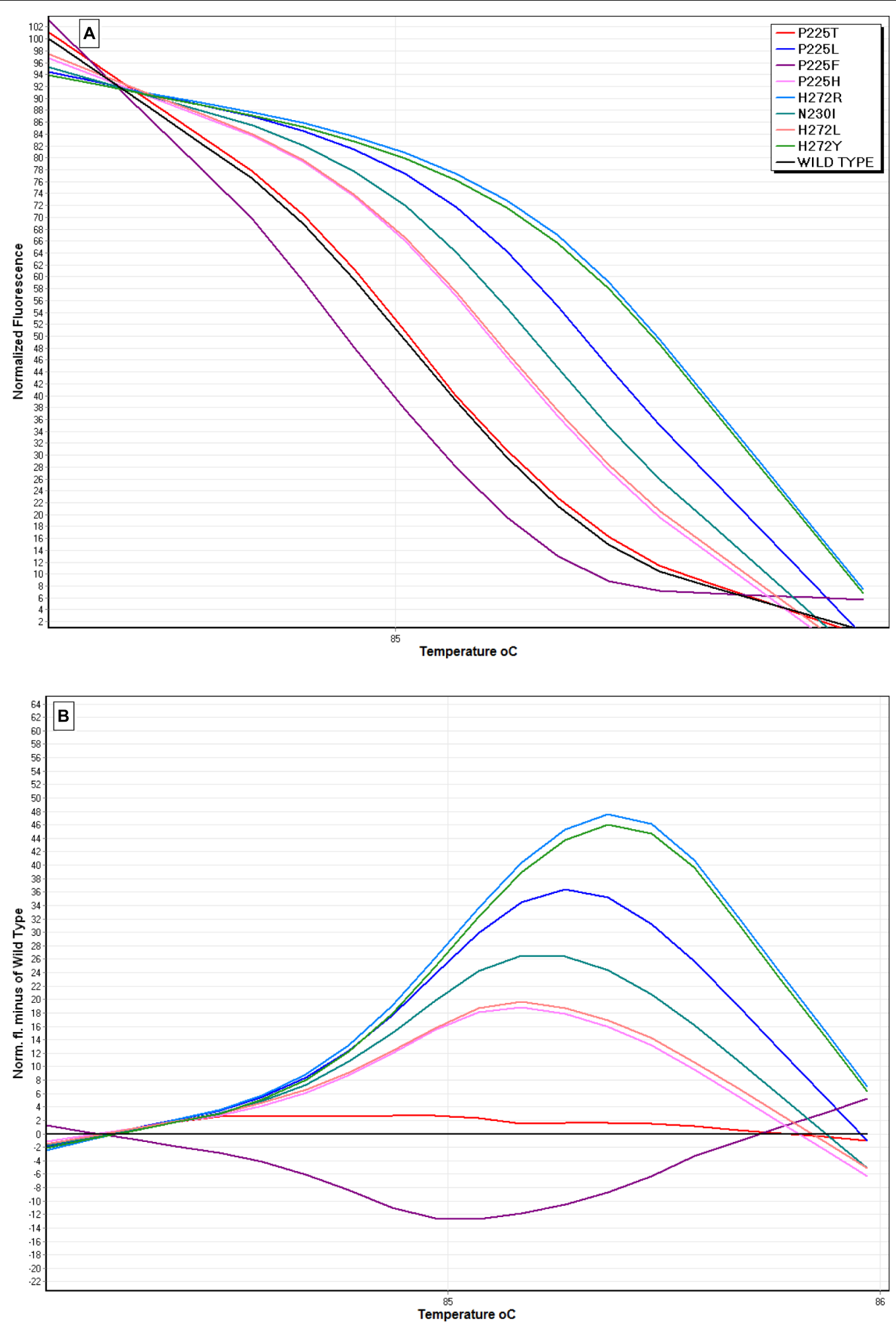

FIGURE 2 | High resolution melting (HRM) analysis using the primers SDHB-Fw and SDHB-Rev for the discrimination of SDHI-resistant B. cinerea isolates possessing the sdhB mutations P225H/T/F/L, H272R/Y/L, and N230I. (A) Normalized HRM curves of isolates with different mutations, (B) Difference curves of HRM using a sensitive isolate as the reference baseline curve. 


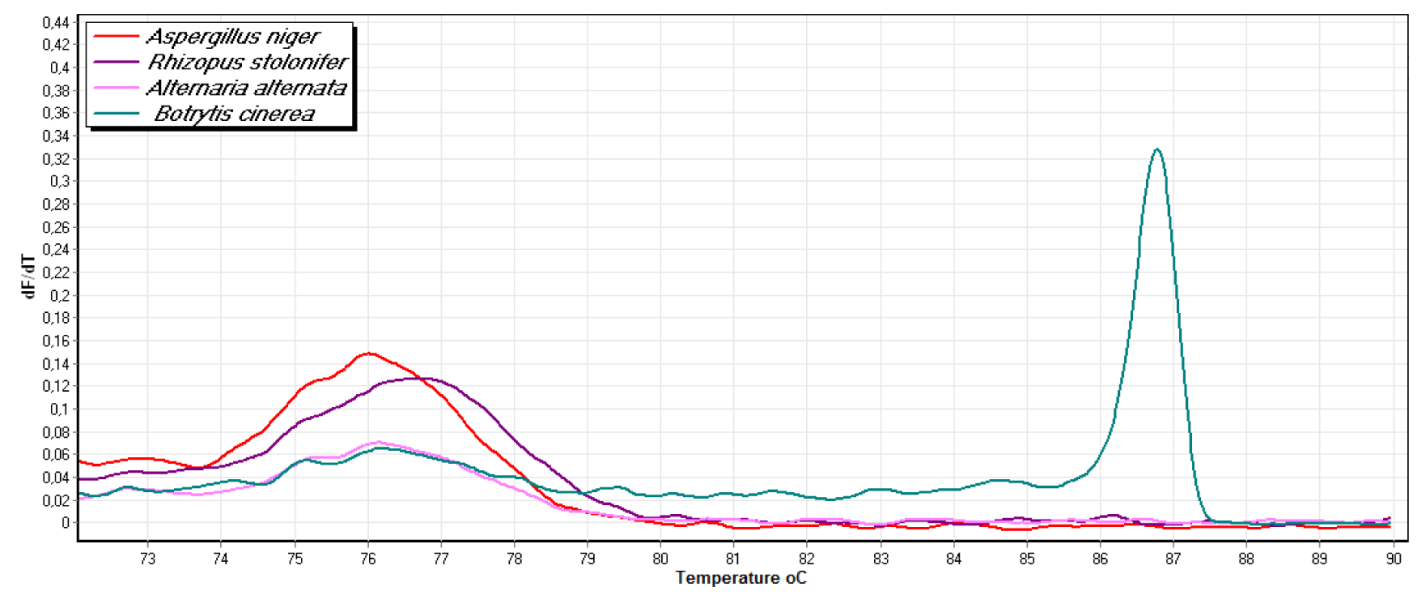

FIGURE 3 | Melting profile of four fungal pathogens, using the specific primers SDHB-Fw and SDHB-Rev with genomic DNA of $B$. cinerea, Aspergillus niger, Rhizopus stolonifer, and Alternaria alternata.

and 1 samples harboring the H72R, H272Y, and N230I mutations, respectively (Table 2). All 30 mutated samples were typed to one of the three above mentioned genotypes with a confidence threshold $>90 \%$. Furthermore, all the three genotypes harboring mutations were clearly discriminated from the non-mutated samples (samples of wild-type sensitivity), (Figure 6). Similarly, in the samples obtained from stone fruit rootstock seedlings HRM analysis showed the presence of 77, 21, and 2 samples possessing the H272R, N230I, and $\mathrm{P} 225 \mathrm{H}$ mutations, respectively (Table 2). The identification results obtained by the application of the HRM analysis were in absolute agreement, for all the samples, with identification data obtained by the standard PIRA-PCR technique. Due to absence of available PIRA-PCR method for the identification of $\mathrm{P} 225 \mathrm{H}$ mutation, the presence of the mutation was confirmed by direct sequencing of the $s d h \mathrm{~B}$ subunit.

\section{DISCUSSION}

The current study was conducted aiming to develop a novel method for rapid identification of $s d h \mathrm{~B}$ mutations in $B$. cinerea isolates with resistance to SDHIs. HRM was selected since it represents a method that is increasingly popular and widespread due to its accuracy, easy, fast, and cost effective application. It has recently been also successfully adopted in a series of research applications that include single base change genotyping, insertion and deletion genotyping sequence matching, methylation profiling, internal tandem duplication detection, and mutation screening (Radvanszky et al., 2015), while it is in its infancy for the detection of mutations associated with the resistance of fungal plant pathogens to fungicides.

Currently, four SDHI molecules (boscalid, penthiopyrad, isopyrazam, and fluopyram) have been registered for use as botryticides in different places of the world, while some additional active ingredients such as benzovindiflupyr and isofetamid, may be introduced into the agricultural practice in the near future (Fillinger and Walker, 2016). The availability of different molecules belonging in the same fungicide class along with the observed variability in $s d h \mathrm{~B}$ mutations associated with resistance to SDHIs makes necessary the development of a rapid method enabling the simultaneous detection of the several $s d h \mathrm{~B}$ mutations. This is particularly important taking into account that the several $s d h \mathrm{~B}$ mutations confer differential levels of resistance to the different SDHI molecules (Veloukas et al., 2013; Amiri et al., 2014; De Miccolis Angelini et al., 2014a). For instance, H272Y mutation confers moderate levels of resistance to boscalid or low levels of resistance to isopyrazam but it is associated with hypersensitivity to fluopyram. Similarly, H272R mutation is associated with moderate levels of resistance to boscalid or isopyrazam but it does not affect the sensitivity of the mutants to fluopyram. In contrast, other mutations such as $\mathrm{H} 272 \mathrm{~L}$ or $\mathrm{P} 225 \mathrm{~F} / \mathrm{L}$ are associated with moderate or high levels of resistance to all the molecules of the SDHI group that are registered as botryticides. Furthermore, recent findings suggest that the different $s d h \mathrm{~B}$ mutations may have adverse effects on the fitness of the mutated strains (Laleve et al., 2014; Veloukas et al., 2014). Although there are some discrepancies among these two studies a common conclusion can be derived suggesting that the different $s d h \mathrm{~B}$ mutations have different impacts on the fitness of the strains. Such differences may have significant implications for the implementation of the management of resistance to SDHIs and therefore, precise knowledge of the population composition in terms of specific mutations presence and their frequency within the population is necessary.

In the recent past several methods were developed for the detection and identification of $s d h \mathrm{~B}$ mutations in $B$. cinerea. These methods were including amplification and direct sequencing of the target gene (Leroux et al., 2010), a PIRA-PCR technique for the detection of H272L/R/Y, P225F, and N230I mutations (Veloukas et al., 2011), an allele-specific PCR assay for the detection of H272R/Y mutations (Yin et al., 2011) or more recently a PCR-RFLP technique for the detection of the N230I mutation (Amiri et al., 2014) and a quantitative real-time allele-specific PCR for the detection of N230I, P225F/L, and 

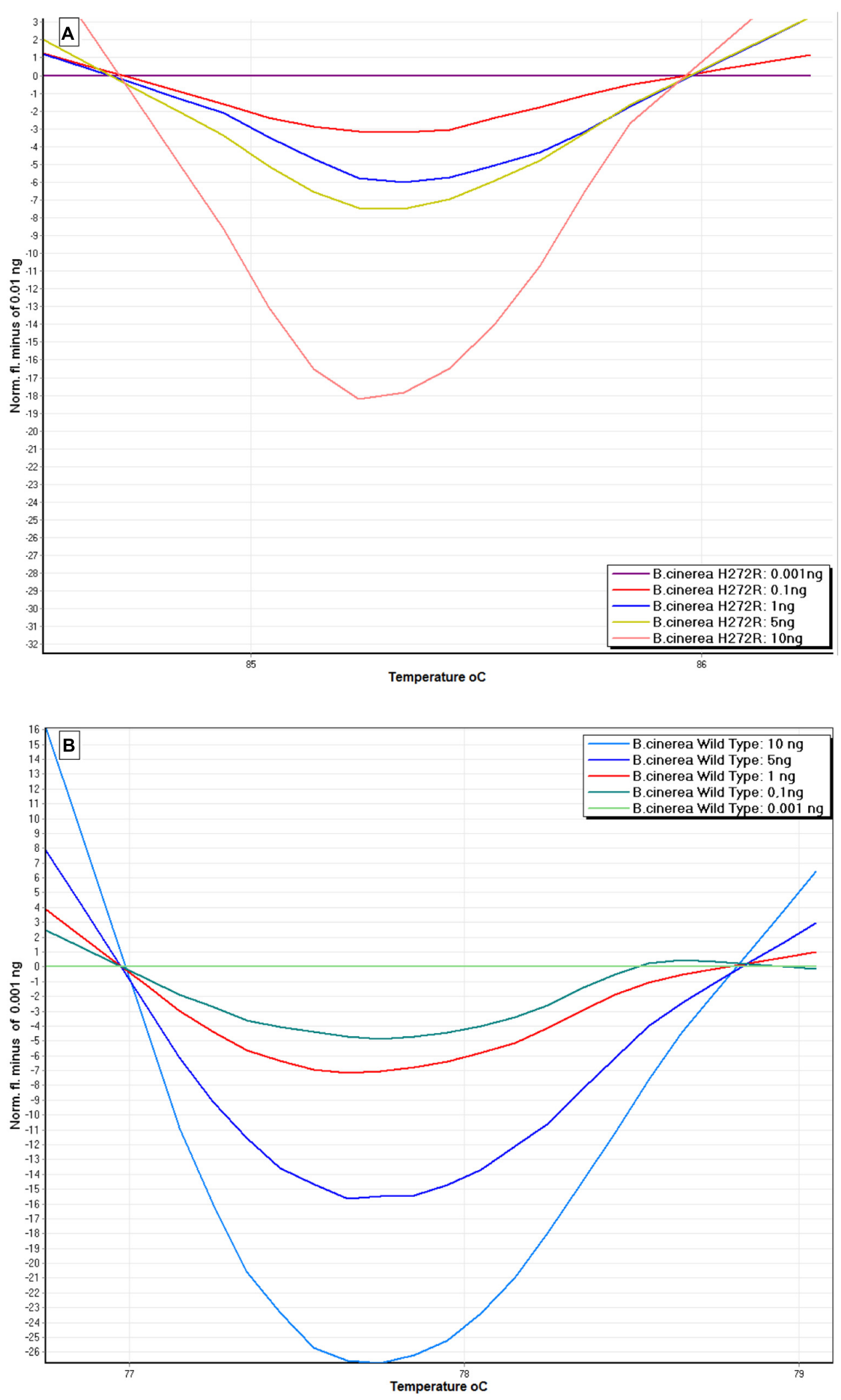

FIGURE 4 | Sensitivity of HRM assay to detect DNA of a B. cinerea isolate possessing the H272R mutation (A) and a wild-type isolate (B). Difference curves were generated using $0.1-10 \mathrm{ng}$ DNA per reaction tube. $0.001 \mathrm{ng}$ of genomic DNA from $B$. cinerea was used as reference baseline curve. 

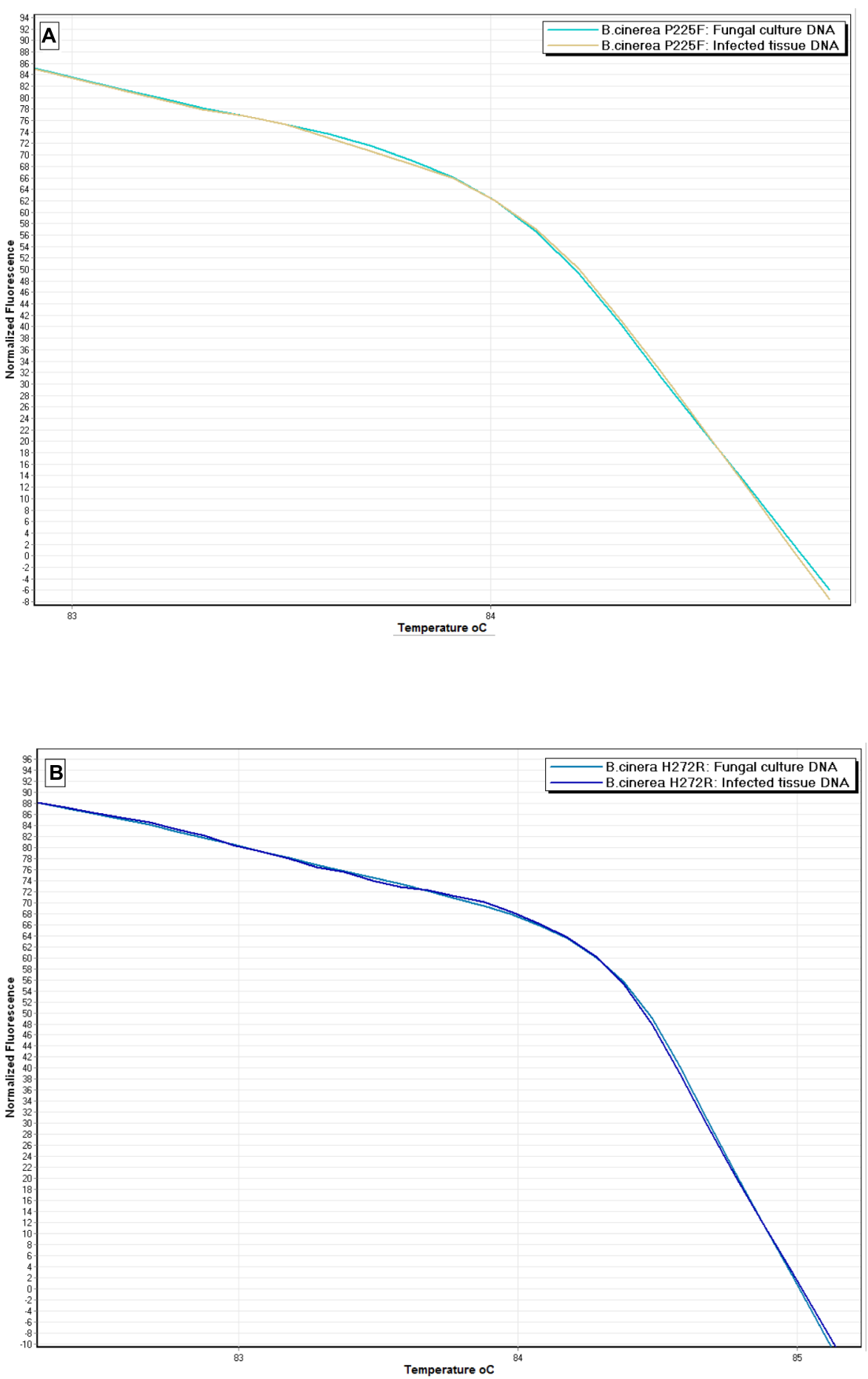

FIGURE 5 | Normalized HRM analysis curves of two B. cinerea isolates possessing P225F (A) and H272R (B) mutations, generated from genomic DNA extracted from a fungal culture and from artificially inoculated strawberry fruit tissue.

H272R/Y/V (De Miccolis Angelini et al., 2014a). However, all these methods require, as a first step, the isolation of the pathogen while, with the exception of the direct gene sequencing, the remaining methods require multiple reactions for the identification of the $s d h \mathrm{~B}$ mutations associated with resistance.
In the present paper the development of a HRM assay for the rapid and simultaneous detection of eight different $s d h \mathrm{~B}$ mutations is described. The assay successfully recognized the eight mutants, as well as the non-mutated strains of wild-type sensitivity to SDHIs. The nine genotypes tested provided melting 
TABLE 2 | Determination of resistance to boscalid and detection of sdhB mutations using high resolution melting (HRM) analysis, PIRA-PCR, and conventional bioassays in $B$. cinerea samples obtained from infected strawberry fruit and stone fruit rootstock seedling plants showing damping-off symptoms.

mutant Host

\begin{tabular}{|c|c|c|c|c|c|c|}
\hline & \multicolumn{3}{|c|}{ Strawberry $\left(n=50^{b}\right)$} & \multicolumn{3}{|c|}{ Stone fruit rootstock seedling plants $\left(n=134^{b}\right)$} \\
\hline & HRM & PIRA-PCR ${ }^{\mathbf{a}}$ & Conventional bioassays ${ }^{c}$ & HRM & PIRA-PCR & Conventional bioassays \\
\hline Wild-type & 20 & $\mathrm{nd}^{\mathrm{d}}$ & 20 & 34 & nd & 34 \\
\hline $\mathrm{H} 272 \mathrm{R}$ & 18 & 18 & $\mathrm{nd}^{\mathrm{e}}$ & 77 & 77 & nd \\
\hline $\mathrm{H} 272 \mathrm{Y}$ & 11 & 11 & nd & 0 & 0 & nd \\
\hline $\mathrm{N} 230 \mathrm{I}$ & 1 & 1 & nd & 21 & 21 & nd \\
\hline P225H & 0 & 0 & nd & 2 & $2^{f}$ & nd \\
\hline
\end{tabular}

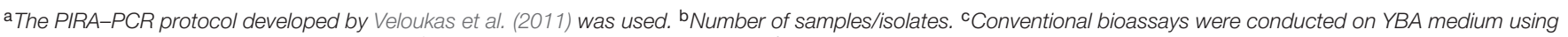

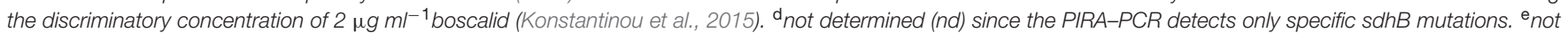

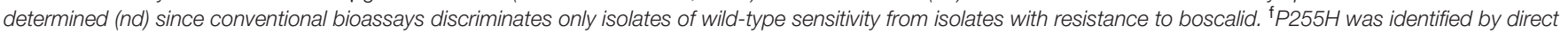
sequencing of the sdhB gene using the primer pair IpBcBeg and lpBcEnd2, designed by Leroux et al. (2010).

curves of the PCR products with distinct and consistent shape and profile, enabling their discrimination. The melting curve profile of a PCR product is affected by several parameters, among which the GC/AT ratio, the length and sequence of the PCR product are included (Ririe et al., 1997; Reed et al., 2007). The primer pair used in this study was designed based on the sequence of the $s d h \mathrm{~B}$ subunit of $B$. cinerea, the subunit in which the most common mutations associated with resistance of this fungus to SDHIs occur (Leroux et al., 2010). The designed primer pair amplified a 249 bp region of the gene in which the three codons, 225, 230, and 272, with possible mutations were included. The size of PCR product was of 249 bp length. Successful application of HRM analysis for SNP scanning requires PCR products of relatively small length. In case of PCR products with a length longer than $400 \mathrm{bp}$ the error rate increases, and the sensitivity of the analysis decreases, while, in contrast, the position of the mutation within the PCR product does not affect the scanning accuracy (Reed and Wittwer, 2004; Reed et al., 2007). Interestingly, the method was found to be highly sensitive enabling discrimination of multiple SNPs located in the same codon (i.e., four different SNPs at codon 225 and three different SNPs at codon 272). Even when the HRM curves might look similar the software of the instrument can identify even slight differences and express these as confidence values which are the numerical data showing the similarities and differences of the different genotypes used in the analysis. Confidence value above $80 \%$ is considered significant. A similar HRM assay developed aiming to discriminate SNPs located at codon 54 of the Cyp51A gene of Aspergillus fumigatus proved to be successful in discriminating the mutated strains from the strains of wild-type sensitivity to the azole fungicides but failed to discriminate the seven different mutants from each other (Tuohy et al., 2010).

The method was capable of discriminating the $s d h \mathrm{~B}$ mutants, included in the study, using as template DNA isolated both from pure fungal cultures or infected fruit tissues. This offers an extra advantage for the test contributing to the rapid identification of $s d h \mathrm{~B}$ mutations without the need for previous isolations of the pathogen. In addition to the rapidity of the assay it was shown that it was highly specific. One of the main problems faced with methods that use DNA directly extracted from the plant tissues is the possible presence of infections by multiple pathogens or contaminants on the tissue surface (Gori et al., 2012). The primer pair designed for the assay specifically discriminated the DNA of $B$. cinerea from that of other fungal species that may infect or may grow as saprophytes on strawberry fruit. Similarly, the simultaneous presence in the infected tissue of different $B$. cinerea strains cannot be excluded. However, taking into account that the assay is highly sensitive it is expected that different genotypes that may co-exist in the tissue sample are easily discriminated.

The developed assay was validated by applying that in unknown Botrytis samples originating from either infected strawberry fruit or infected seedlings of stone fruit rootstocks showing damping-off symptoms. The data obtained by the HRM analysis were compared with the data derived by the phenotyping of the isolates using a conventional bioassay technique as well as by the application of a standard PIRA-PCR technique developed by Veloukas et al. (2011) to identify P225F, N230I, and H272L/R/Y mutations. The comparison showed that the HRM assay can distinguish the isolates of wild-type sensitivity from the $s d h \mathrm{~B}$ mutants that were found to be phenotypically resistant to boscalid, while in addition the assay enabled the detection of the $s d h \mathrm{~B}$ mutations in the SDHI-resistant samples. In regards of $s d h \mathrm{~B}$ mutation detection the HRM assay provided similar results with the standard PIRA-PCR technique or the sequencing of the entire gene.

Both crops that were monitored by the HRM assay are heavily treated with fungicides against B. cinerea. In Greece strawberries are cultivated under high height plastic tunnels and more than six spray fungicide applications are required for successful control of the disease. Similarly, stone fruit rootstock seedling plants are transferred after their generation by micro-propagation in the greenhouse for acclimatization and initial growth. Their need for constant high humidity creates a microenvironment extremely favorable for the development of the disease and for its control successive applications of botryticides are required. HRM analysis showed that, on both hosts, the substitution of histidine by arginine at codon 272 (H272R) was the most common mutation in the SDHI-resistant fraction of the fungal 

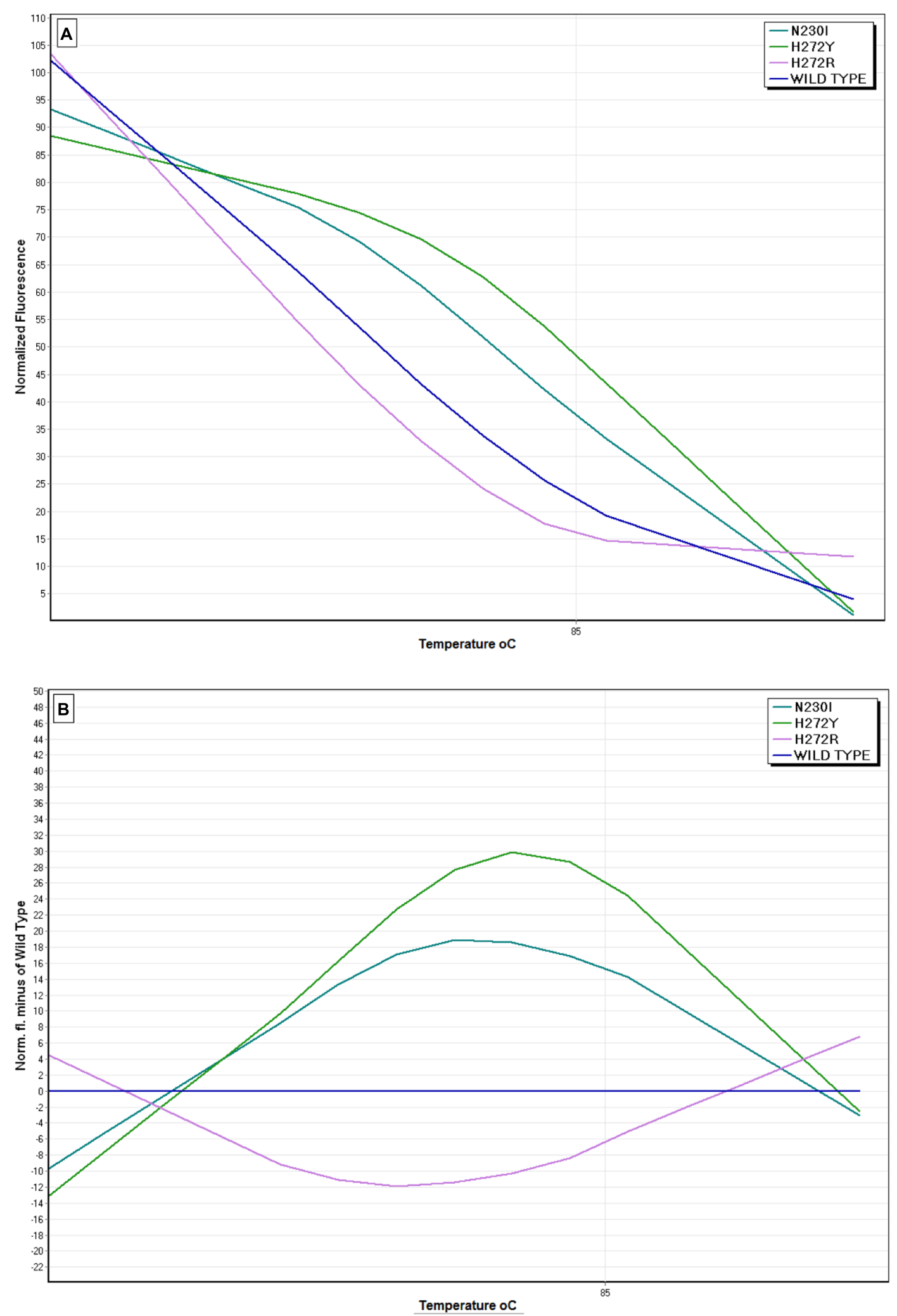

FIGURE 6 | Representative HRM analysis curves of four B. cinerea genotypes generated from unknown field samples. (A) Normalized HRM curves of DNA samples with H27R/Y and N230I mutations and one non-mutated DNA sample (wild-type), (B) Difference graph of HRM curves using the non-mutated (wild-type) sample as the reference baseline curve. 
populations. This is in agreement with numerous previous monitoring studies from all over the world suggesting that $\mathrm{H} 272 \mathrm{R}$ is currently the most common mutation associated with resistance to SDHIs in B. cinerea (Leroux et al., 2010; Veloukas et al., 2011; Fernandez-Ortuno et al., 2012; De Miccolis Angelini et al., 2014a). Other mutations such as H272Y or N230I were found in lower frequencies, while $\mathrm{P} 225 \mathrm{H}$ was detected in a very low frequency in the population originating from stone fruit rootstock seedlings. $\mathrm{P} 225 \mathrm{H}$ mutation is a rather rare mutation that, till now, has been reported only in $B$. cinerea originating from stone fruit rootstock seedlings in Greece (Konstantinou et al., 2014) and from table grapes in Chile (Esterio et al., 2015). In most of the monitoring studies published previously these mutations are rare or in lower frequencies compared to the frequency of H272R mutation. This is probably correlated with a fitness cost that has been confirmed recently both for isogenic and field strains of the pathogen possessing mutations such as the N230I, P225L/F, or the H272L (Laleve et al., 2014; Veloukas et al., 2014).

The HRM protocol developed in the current study has many advantages compared to other methods developed previously for the detection of $s d h \mathrm{~B}$ mutations in $B$. cinerea (Veloukas et al., 2011; Yin et al., 2011; Amiri et al., 2014). The most important one is the fact that expands the detection spectrum to all the currently known $s d h \mathrm{~B}$ mutations, conferring resistance to SDHIs in $B$. cinerea. In total, by this method eight different mutations can be detected in a single reaction. In addition, the developed protocol enables the detection of sequence variations within the PCR product without the need of a separation step achieved by gel electrophoresis that is required in older molecular methods. This separation often takes hours to perform and increase the risk for contamination. Furthermore, the developed assay allows the handling of several samples in a single reaction, while older methods necessitate the application of several reactions, often with the need for changing primers. In general, the HRM analysis is a single tube post PCR reaction which is fast, highly accurate, and cost effective since does not require gel analysis or sequencing of the PCR products or any other post PCR treatment.

However, the developed method has also some limitations. Among these the most important one is that there is a controversial need for reference controls. The simultaneous presence of both the reference and the unknown samples allows direct comparison of the melting curves, since it is possible that slight variations in the confidence levels may occur between runs (Robertson et al., 2009; Wong et al., 2013). However, this disadvantage might be overcome by obtaining a melting curve database to serve as standard (Madesis et al., 2014). Another disadvantage of the developed method is that it is a qualitative one and does not offer quantitative data for the frequency of each genetic substitution within a pathogen' population. However, it has been proposed that HRM analysis can be combined with qPCR in case that quantitative data are required (Rouleau et al., 2009). Currently, the only available method for quantitative assessment of $s d h \mathrm{~B}$ mutants in $B$. cinerea is a recently developed pyrosequencing-based method (GobeilRichard et al., 2015). A third disadvantage of the method that has to be taken into account, when it is applied in fungicide resistance monitoring programs, is the probability for the presence of natural polymorphisms in the amplified products that might change the melting profile of the amplicon leading to false results. Such polymorphisms are not necessarily associated with resistance to SDHIs (e.g., silent mutations). Actually, this probability is very high when genes with high frequency of natural polymorphisms are amplified, such as, for instance, the 3-ketoreductase ( $\operatorname{erg} 27)$ gene, the target site of hydroxyaniline fungicides (Grabke et al., 2013). Yet, in the case of $s d h \mathrm{~B}$ mutants the probability is low since the gene is considered to be highly conserved and natural polymorphisms are very rare. In addition, as already stated the amplified part of the genome by the designed primer pair, is not excessively long and the risk for natural polymorphisms existence is further reduced.

The development of fungicide resistance in $B$. cinerea populations is one of the major limiting factors of successful control of the pathogen (Hahn, 2014). SDHIs, in particular, as being one of the latest pesticide additions used against the pathogen may play a crucial role in the implementation of anti-resistance strategies since they do not show cross-resistance relationships with fungicides of other chemical classes in which the pathogen has already developed resistance. But taking into account, that they are also fungicides of medium to high risk for resistance development, continuous monitoring are required for sensitivity measurements and detection of specific pathogen mutants with resistance to this fungicide class. In conclusion, the HRM method developed in the current study could easily be adopted as the method of choice for a rapid identification of $s d h \mathrm{~B}$ mutations in $B$. cinerea using pathogen DNA either extracted from pathogen colonies or from infected plant tissues from laboratories that are equipped with the necessary instruments. Due to its low cost and the reduction in time required to obtain results it can be applied in programs aiming to monitor the presence of specific $s d h \mathrm{~B}$ mutations in pathogens' populations in crops that heavily treated with botryticides. Such knowledge is a prerequisite for the successful implementation of strategies aiming to prolong the use of SDHIs as botryticides.

\section{AUTHOR CONTRIBUTIONS}

GK and PM conceived and designed the experiments. AS performed all experiments, analyzed the data, and wrote part of the paper. GK supervised the study and wrote the paper. All authors read and approved the final manuscript.

\section{FUNDING}

This research has been co-financed by the European Union [European Social Fund (ESF)]+ and Greek national funds through the Operational Program "Education and Lifelong Learning" of the National Strategic Reference FrameworkResearch Funding Program THALES, project M15380264, 
entitled "Development of IT and molecular diagnostics tools for improving the sustainability of pesticide based approaches to control agricultural pests of major economic importance in Greece."

\section{REFERENCES}

Amiri, A., Heath, S. M., and Peres, N. A. (2014). Resistance to fluopyram, fluxapyroxad, and penthiopyrad in Botrytis cinerea from strawberry. Plant Dis. 98, 532-539. doi: 10.1094/PDIS-07-13-0753-RE

Bardas, G. A., Veloukas, T., Koutita, O., and Karaoglanidis, G. S. (2010). Multiple resistance of Botrytis cinerea from kiwifruit to SDHIs, QoIs and fungicides of other chemical groups. Pest Manag. Sci. 66, 966-973. doi: 10.1002/ps.1968

Bester, R., Jooste, A. E., Maree, H. J., and Burger, J. T. (2012). Realtime RT-PCR high-resolution melting curve analysis and multiplex RT-PCR to detect and differentiate grapevine leafroll-associated virus 3 variant groups I, II, III and VI. Virol. J. 9:219. doi: 10.1186/1743-422x-9-219

Cecchini, G. (2003). Function and structure of complex II of the respiratorychain. Annu. Rev. Biochem. 72, 77-109. doi: 10.1146/annurev.biochem.72.121801.161700

Chatzidimopoulos, M., Papaevagellou, D., and Pappas, A. C. (2013). Detection and characterization of fungicide resistant phenotypes of Botrytis cinerea in lettuce crops in Greece. Eur. J. Plant Pathol. 137, 363-376. doi: 10.1007/s10658-0130248-x

Chatzidimopoulos, M., Ganopoulos, I., Madesis, P., Vellios, E., Tsaftaris, A., and Pappas, A. C. (2014). High-resolution melting analysis for rapid detection and characterization of Botrytis cinerea phenotypes resistant to fenhexamid and boscalid. Plant Pathol. 63, 1336-1343. doi: 10.1111/ppa.12210

Curvers, K., Pycke, B., Kyndt, T., Vanrompay, D., and Haesaert, G. (2015). A high-resolution melt (HRM) assay to characterize CYP51 haplotypes of the wheat pathogen Mycosphaerella graminicola. Crop Prot. 71, 12-18. doi: 10.1016/j.cropro.2015.01.018

De Miccolis Angelini, R. M., Rotolo, C., Masiello, M., Gerin, D., Pollastro, S., and Faretra, F. (2014a). Molecular characterization and detection of resistance to succinate dehydrogenase inhibitor fungicides in Botryotinia fuckeliana (Botrytis cinerea). Pest Manag. Sci. 70, 1884-1893. doi: 10.1002/ps.3748

De Miccolis Angelini, R. M., Rotolo, C., Masiello, M., Gerin, D., Pollastro, S., and Faretra, F. (2014b). Occurrence of fungicide resistance in populations of Botryotinia fuckeliana (Botrytis cinerea) on table grape and strawberry in southern Italy. Pest Manag. Sci. 70, 1785-1796. doi: 10.1002/ps.3711

Dean, R., Van Kan, J. A. L., Pretorius, Z. A., Hammond-Kosack, K. E., Di Pietro, A., Spanu, P. D., et al. (2012). The top 10 fungal pathogens in molecular plant pathology. Mol. Plant Pathol. 13, 414-430. doi: 10.1111/j.13643703.2011.00783.x

Esterio, M., Araneda, M. J., Roman, A., Pizzaro, L., Copier, C., and Auger, J. (2015). First report of boscalid resistant Botrytis cinerea isolates carrying the mutations H272R, H272Y, P225L, and P225H from table grape in Chile. Plant Dis. 99:891. doi: 10.1094/pdis-12-14-1257-pdn

Fernandez-Ortuno, D., Chen, F., and Schnabel, G. (2012). Resistance to pyraclostrobin and boscalid in Botrytis cinerea isolates from strawberry in the Carolinas. Plant Dis. 96, 1198-1203. doi: 10.1094/pdis-12-11-1049-re

Fillinger, S., and Walker, A.-S. (2016). "Chemical control and resistance management of Botrytis diseases," in Botrytis-the Fungus, the Pathogen and its Management in Agricultural Systems, eds S. Fillinger and Y. Elad (Berlin: Springer).

FRAC (2016). FRAC MOA Poster [Online]. Fungicide Resistance Action Committee. Available at: www.frac.info

Ganopoulos, I., Madesis, P., Zambounis, A., and Tsaftaris, A. (2012). Highresolution melting analysis allowed fast and accurate closed-tube genotyping of Fusarium oxysporum formae specialis complex. FEMS Microbiol. Lett. 334, 16-21. doi: 10.1111/j.1574-6968.2012.02610.x

Gobeil-Richard, M., Tremblay, D-M., Beaulieu, C., van der Heyden, H., and Carisse, O. (2015). A pyrosequencing-based method to quantify genetic substitutions associated with resistance to succinate dehydrogenase inhibitor fungicides in Botrytis spp. populations. Pest Manag. Sci. 72, 566-573. doi: $10.1002 /$ ps.4026

\section{ACKNOWLEDGMENT}

We thank Dr. Gerd Stammler (BASF, Limburgerhof, Germany) for providing the $\mathrm{P} 225 \mathrm{~L} / \mathrm{T}$ mutants included in the study.

Gori, A., Cerboneschi, M., and Tegli, S. (2012). High-Resolution melting analysis as a powerful tool to discriminate and genotype Pseudomonas savastanoi pathovars and strains. PLoS ONE 7:e30199. doi: 10.1371/journal.pone.0030199

Grabke, A., Fernández-Ortuño, D., and Schnabel, G. (2013). Fenhexamid resistance in Botrytis cinerea from strawberry fields in the Carolinas is associated with four target gene mutations. Plant Dis. 97, 271-276. doi: 10.1094/pdis-06-12-0587-re

Hahn, M. (2014). The rising threat of fungicide resistance in plant pathogenic fungi: Botrytis as a case study. J. Chem. Biol. 7, 133-141. doi: 10.1007/s12154014-0113-1

Kim, Y. K., and Xiao, C. L. (2010). Resistance to pyraclostrobin and boscalid in populations of Botrytis cinerea from stored apples in Washington State. Plant Dis. 94, 604-612. doi: 10.1094/pdis-94-5-0604

Konstantinou, S., Sarmis, G., and Karaoglanidis, G. S. (2014). Population structure and fungicide resistance profile of Botrytis spp. causing damping-off disease in stone and pome fruit rootstock seedlings. Phytopathology 104 (Suppl. 3):S3.62.

Konstantinou, S., Veloukas, T., Leroch, M., Menexes, G., Hahn, M., and Karaoglanidis, G. S. (2015). Population structure, fungicide resistance profile, and $\mathrm{sdhB}$ mutation frequency of Botrytis cinerea from strawberry and greenhouse-grown tomato in Greece. Plant Dis. 99, 240-248. doi: 10.1094/pdis04-14-0373-re

Laleve, A., Fillinger, S., and Walker, A.-S. (2014). Fitness measurements reveals contrasting costs in homologous recombinant mutants of Botrytis cinerea resistant to succinate dehydrogenase inhibitors. Fungal Genet. Biol. 67, 24-36. doi: 10.1016/j.fgb.2014.03.006

Leroch, M., Kretschmer, M., and Hahn, M. (2011). Fungicide resistance phenotypes of Botrytis cinerea isolates from commercial vineyards in south west Germany. J. Phytopathol. 159, 63-65. doi: 10.1111/j.1439-0434.2010.01719.x

Leroux, P. (2007). "Chemical control of Botrytis and its resistance to chemical fungicides," in Botrytis: Biology, Pathology and Control, eds Y. Elad, B. Williamson, P. Tudzynskiand and N. Delen (Dordrecht: Springer), 195-222. doi: 10.1007/978-1-4020-2626-3_12

Leroux, P., Gredt, M., Leroch, M., and Walker, A-S. (2010). Exploring mechanisms of resistance to respiratory inhibitors in field strains of Botrytis cinerea, the causal agent of gray mold. Appl. Environ. Microbiol. 76, 6615-6630.

Madesis, P., Ganopoulos, I., Sakaridis, I., Argiriou, A., and Tsaftaris, A. (2014). Advances of DNA-based methods for tracing the botanical origin of food products. Food Res. Int. 60, 163-172. doi: 10.1016/j.foodres.2013. 10.042

Mondini, L., Nachit, M. M., and Pagnotta, M. A. (2015). Allelic variants in durum wheat (Triticum turgidum L. var. durum) DREB genes conferring tolerance to abiotic stresses. Mol. Genet. Genom. 290, 531-544. doi: 10.1007/s00438-0140933-2

Mondini, L., Nachit, M. M., Porceddu, E., and Pagnotta, M. A. (2011). HRM technology for the identification and characterization of INDEL and SNP mutations in genes involved in drought and salt tolerance of durum wheat. Plant Genet. Res. 9, 166-169. doi: 10.1017/S1479262111000517

Mondini, L., Nachit, M. M., Porceddu, E., and Pagnotta, M. A. (2012). Identification of SNP mutations in DREB1, HKT1 and WRKY1 genes involved in drought and salt stress tolerance in durum wheat (Triticum turgidum L. var. durum). OMICS 16, 178-187. doi: 10.1089/omi.2011.0081

Myresiotis, C. K., Karaoglanidis, G. S., and Tzavella-Klonari, K. (2007). Resistance of Botrytis cinerea isolates from vegetable crops to anilinopyrimidine, phenylpyrrole, hydroxyanilide, benzimidazole, and dicarboximide fungicides. Plant Dis. 91, 407-413. doi: 10. (1094)/PDIS-91-4-0407

Papavasileiou, A., Madesis, P. B., and Karaoglanidis, G. S. (2016). Identification and differentiation of Monilinia species causing brown rot of pome and stone fruit using High-Resolution Melting (HRM) analysis. Phytopathology 106, 1055-1064. doi: 10.1094/phyto-01-16-0016-r

Plesken, C, Weber, R. W. S., Rupp, S., Leroch, M., and Hahn, M. (2015). Botrytis pseudocinerea is a significant pathogen of several crop plants but susceptible to 
displacement by fungicide-resistant B. cinerea strains. Appl. Environ. Microbiol. 81, 7048-7056. doi: 10.1128/aem.01719-15

Radvanszky, J., Surovy, M., Nagyova, E., Minarik, G., and Kadasi, L. (2015). Comparison of different DNA binding fluorescent dyes for applications of high-resolution melting analysis. Clin. Biochem. 48, 609-616. doi: 10.1016/j.clinbiochem.2015.01.010

Reed, G. H., and Wittwer, C. T. (2004). Sensitivity and specificity of singlenucleotide polymorphism scanning by High-Resolution Melting analysis. Clin. Chem. 50, 1748-1754. doi: 10.1373/clinchem.2003.029751

Reed, G. H., Kent, J. O., and Wittwer, C. T. (2007). High-resolution DNA melting analysis for simple and efficient molecular diagnostics. Pharmacogenomics 8, 597-608. doi: 10.2217/14622416.8.6.597

Ririe, K. M., Rasmussen, R. P., and Wittwer, C. T. (1997). Product differentiation by analysis of DNA melting curves during the polymerase chain reaction. Anal. Biochem. 245, 154-160. doi: 10.1006/abio.1996.9916

Robertson, T., Bibby, S., O’Rourke, D., Belfiore, T., Lambie, H., and Noormohammadi, A. H. (2009). Characterization of Chlamydiaceae species using PCR and high resolution melt curve analysis of the 16SrRNA gene. J. Appl. Microbiol. 107, 2017-2028. doi: 10.1111/j.1365-2672.2009. 04388.x

Rouleau, E., Lefol, C., Bourdon, V., Coulet, F., Noguchi, T., Soubrier, F., et al. (2009). Quantitative PCR high-resolution melting (qPCR-HRM) curve analysis, a new approach to simultaneously screen point mutations and large rearrangements: application toMLH1 germline mutations in LynchSyndrome. Hum. Mutat. 30, 867-875. doi: 10.1002/humu.20947

Sakaridis, I., Ganopoulos, I., Soultos, N., Madesis, P., Tsaftaris, A., and Argiriou, A. (2014). Identification of lactic acid bacteria isolated from poultry carcasses by high-resolution melting (HRM) analysis. Eur. Food Res. Technol. 238, 691-697. doi: 10.1007/s00217-013-2134-3

Stammler, G., Brix, H. D., Nave, B., Gold, R., and Schoefl, U. (2008). "Studies on the biological performance of boscalid and its mode of action," in Modern Fungicides and Antifungal Compounds V. eds H. W. Dehne, H. B. Deising, U. Gisi, P. E. Russell and H. Lyr (Braunschweig: Deutsche Phytomedizinische Gesellschaft), 45-51. doi: 10.1016/s0031-9422(99)00417-3

Taylor, C. F. (2009). Mutation scanning using high-resolution melting. Biochem. Soc. Trans. 37, 433-437. doi: 10.1042/BST0370433
Tuohy, M. J., Reja, V., Park, S., Perlin, D. S., Wnek, M., Procop, G. W., et al. (2010). Use of a high-resolution melt assay to characterize codon54 of the cyp51A gene of Aspergillus fumigatus on a Rotor-Gene 6000 instrument. Antimicrob. Agents Chem. 54, 2248-2251. doi: 10.1128/aac.01712-09

Veloukas, T., and Karaoglanidis, G. S. (2012). Biological activity of the succinate dehydrogenase inhibitor fluopyram against Botrytis cinerea and fungal baseline sensitivity. Pest Manag. Sci. 68, 858-864. doi: 10.1002/ps.3241

Veloukas, T., Leroch, M., Hahn, M., and Karaoglanidis, G. S. (2011). Detection and molecular characterization of boscalid-resistant Botrytis cinerea isolates from strawberry. Plant Dis. 95, 1302-1307. doi: 10.1094/pdis-04-11-0317

Veloukas, T., Markoglou, A. N., and Karaoglanidis, G. S. (2013). Differential effect of SdhB gene mutations on the sensitivity to SDHI fungicides in Botrytis cinerea. Plant Dis. 97, 118-122. doi: 10.1094/pdis-03-12-0322-re

Veloukas, T., Kalogeropoulou, P., Markoglou, A. N., and Karaoglanidis, G. S. (2014). Fitness and competitive ability of Botrytis cinerea field-isolates with dual resistance to SDHI and QoI fungicides, associated with several sdhB and the cytb G143A mutations. Phytopathology 104, 347-356. doi: 10.1094/phyto-0713-0208-r

Wong, M. H., Henderson, J., and Drent, A. (2013). Identification and differentiation of Phyllosticta species causing freckle disease of banana using high resolution melting (HRM) analysis. Plant Pathol. 62, 1285-1293. doi: 10.1111/ppa.12056

Yin, Y. N., Kim, Y. K., and Xiao, C. L. (2011). Molecular characterization of boscalid resistance in field isolates of Botrytis cinerea from apple. Phytopathology 101, 986-995. doi: 10.1094/phyto-01-11-0016

Conflict of Interest Statement: The authors declare that the research was conducted in the absence of any commercial or financial relationships that could be construed as a potential conflict of interest.

Copyright $\odot 2016$ Samaras, Madesis and Karaoglanidis. This is an open-access article distributed under the terms of the Creative Commons Attribution License (CC BY). The use, distribution or reproduction in other forums is permitted, provided the original author(s) or licensor are credited and that the original publication in this journal is cited, in accordance with accepted academic practice. No use, distribution or reproduction is permitted which does not comply with these terms. 